\title{
Relation of fetal and infant growth to plasma fibrinogen and factor VII concentrations in adult life
}

\author{
D J P Barker, T W Meade, C H D Fall, A Lee, C Osmond, K Phipps, Y Stirling
}

\begin{abstract}
'Objective-To determine whether reduced fetal and infant growth are associated with higher plasma fibrinogen and factor VII concentrations in adult life. Design-Follow up study of men born during 1920-30 whose weights at birth and at 1 year had been recorded by health visitors, and men born during 1935-43 whose size at birth had been measured in detail.

Setting-Hertfordshire and Preston, England.

Subjects-591 men born in east Hertfordshire who still lived there and 148 men born in Preston who still lived in or close to the city.

Main outcome measures-Plasma fibrinogen and factor VII concentrations.

Results-Among men in Hertfordshire mean plasma fibrinogen and factor VII concentrations fell with increasing weight at 1 year (from $3 \cdot 21 \mathrm{~g} / 1$ in men of $\leqslant 18 \mathrm{lb}$ to $2.93 \mathrm{~g} / \mathrm{l}$ in men of $\geqslant 27 \mathrm{lb}$ and from $122 \%$ of standard to $103 \%$; $<<0.001, p<0.005$ respectively). The trends were independent of cigarette smoking, alcohol consumption, body mass index, and social class. Neither plasma fibrinogen nor factor VII concentration was related to birth weight. In men in Preston, however, fibrinogen concentration fell progressively as the ratio of placental weight to birth weight decreased $(p=0.01)$.

Conclusions-Reduced growth in fetal life and infancy is strongly related to high plasma concentrations of the haemostatic factors fibrinogen and factor VII. This may be a persisting response to impaired liver development during a critical early period.
\end{abstract}

\section{Introduction}

Findings in several recent studies suggest that retarded growth in utero and during infancy is associated with the development of cardiovascular disease in adult life. ${ }^{1}$ Among men born 70 years ago, whose early growth was recorded, those who had lower birth weights and weights at 1 year had higher death rates from ischaemic heart disease. ${ }^{2}$ There were threefold differences in death rates between men with the lowest and highest early weights.

These findings pose the question of which processes associated with retarded early growth lead to ischaemic heart disease. High plasma concentrations of two haemostatic factors, fibrinogen and factor VII, are independently associated with increased rates of the disease. $^{3}$ They may predispose to thrombosis and contribute to the development and progression of atheroma. ${ }^{4}$ Their association with ischaemic heart disease is at least as strong as that of high plasma cholesterol concentration. ${ }^{3}$ We therefore examined whether retarded early growth is associated with higher plasma concentrations of fibrinogen and factor VII.

We measured plasma concentrations of these haemostatic factors in two groups, one group comprising men aged around 64 years whose weight gain in infancy had been recorded, and the other men aged around 50 years whose size at birth had been measured in detail.
Subjects and methods

In Hertfordshire, from 1911 onwards, each birth was notified by the attending midwife. ${ }^{2} \mathrm{~A}$ health visitor saw the child at home periodically throughout infancy. She recorded birth weight, weight at 1 year, method of infant feeding, and illnesses during the first year of life. Weights were measured in pounds $(1 \mathrm{lb}=0.45 \mathrm{~kg})$ and were often rounded to the nearest half pound or pound. We therefore used the original units. We traced singleton boys born in east Hertfordshire during 192030 who had both birth weight and weight at 1 year recorded; 1157 of them still lived there, and 845 agreed to be interviewed at home. They were visited by one of four fieldworkers, ${ }^{5}$ who had not seen the infant data recorded for the man. Height was measured with a portable stadiometer and weight with a portable Seca scale. The waist circumference and hip girth were measured. Blood pressure was measured with an automated recorder (Dinamap) with the man sitting down. Readings were taken on the left arm using the cuff size recommended for the arm circumference. Two readings were taken and the average used in the analysis. Room temperature was recorded. The man was asked about his social history and smoking and drinking habits. Alcohol consumption was converted to the total number of units each week ( 1 unit $=10 \mathrm{ml}$ ethanol). Father's occupation was used to define social class at birth, and current social class was derived from the man's occupation. ${ }^{6}$ Before the study was started the procedures used for the measurements were standardised and the fieldworkers were trained.

After the interview men were asked to attend a local clinic to have a blood sample taken; in 606 blood was taken with minimum haemostasis and analysed for fibrinogen and factor VII concentrations. Thrombin clottable fibrinogen concentration was measured by the Clauss method, with an electrical impedance end point. ${ }^{7}$ Factor VII concentration was measured by a one stage assay with bovine adsorbed deficient plasma and rabbit brain thromboplastin. ${ }^{8}$

In Preston a standardised record form had been kept for each woman admitted to the labour ward at Sharoe Green Hospital during 1935-43.9 The record included the date of the mother's last menstrual period and the baby's birth weight, placental weight, length from crown to heel, and head circumference. Weights were measured in pounds and lengths and head circumferences in inches $(1 \mathrm{in}=2.54 \mathrm{~cm})$. Measurements had often been rounded and we therefore preserved the original units. The babies were not followed up after discharge.

Two hundred and fifty two of the singleton boys born during 1935-43 still lived in Lancashire; 236 agreed to be interviewed at home and were visited by one of four fieldworkers. Blood pressure, weight, height, waist circumference, and hip girth were recorded as for the Hertfordshire men; the results have been reported. ${ }^{9}$ Social class was defined as in the Hertfordshire men. Of 204 men living in or close to Preston who were asked to attend Sharoe Green Hospital to have a blood sample taken, $148 \mathrm{did}$ so. Blood was taken with minimum haemostasis and analysed for fibrinogen and factor VII concentrations
Correspondence to

Professor Barker.

BMF 1992;304: 148-52
BMJ VOLUME 304

18 JANUARY 1992 
by the same methods as used for the samples from Hertfordshire men.

As plasma fibrinogen and factor VII concentrations have skewed distributions we transformed them in the analysis by using logarithms. We used multiple regression to analyse the data.

\section{Results}

\section{HERTFORDSHIRE MEN}

Satisfactory measurements of fibrinogen and factor VII concentrations were obtained for 591 and 582 men respectively; 597 men had one or both measurements performed. Plasma fibrinogen concentration increased by $0.03 \mathrm{~g} / 1$ with each year of age from 59 to 70 years, and we therefore adjusted the concentrations for age. Plasma factor VII concentration was not related to age.

Both mean plasma fibrinogen and factor VII concentrations fell with increasing weight at 1 year (table I). These trends were strongly significant $(p<0.001$, p $<0.005$ respectively). Neither factor showed a significant trend with birth weight $(p=0 \cdot 10, p=0 \cdot 84$ respectively), though the highest concentration of each was found in men with birth weights of $5.5 \mathrm{lb}$ or less.

TABLE I-Mean plasma fibrinogen and factor VII concentrations and systolic blood pressure in Hertfordshire men aged 59-70 according to weight at 1 year and birth weight

\begin{tabular}{|c|c|c|c|c|}
\hline & No of men & $\begin{array}{c}\text { Fibrinogen }(\mathrm{g} / \mathrm{l}) \\
\text { (adjusted for age) }\end{array}$ & $\begin{array}{c}\text { Factor VII } \\
\text { (\% of standard })\end{array}$ & $\begin{array}{c}\text { Systolic pressure ( } \mathrm{mm} \mathrm{Hg} \text { ) } \\
\text { (adjusted for age and room } \\
\text { temperature) }\end{array}$ \\
\hline \multicolumn{5}{|c|}{ Weight at 1 year $(\mathrm{lb})$ : } \\
\hline$\leqslant 18$ & 38 & $3 \cdot 21$ & 122 & 167 \\
\hline-20 & 93 & $3 \cdot 10$ & 111 & 167 \\
\hline-22 & 178 & $3 \cdot 13$ & 108 & 166 \\
\hline-24 & 173 & 2.97 & 106 & 162 \\
\hline-26 & 82 & 2.93 & 106 & 164 \\
\hline$>26$ & 33 & 2.93 & 103 & 162 \\
\hline \multicolumn{5}{|c|}{ Birth weight (lb): } \\
\hline$\leqslant 5.5$ & 21 & $3 \cdot 18$ & 118 & 174 \\
\hline$-6 \cdot 5$ & 70 & 3.06 & 104 & 165 \\
\hline$-7 \cdot 5$ & 187 & $3 \cdot 10$ & 108 & 166 \\
\hline$-8 \cdot 5$ & 183 & $2 \cdot 98$ & 107 & 164 \\
\hline$-9 \cdot 5$ & 96 & 3.00 & 112 & 161 \\
\hline$>9.5$ & 40 & 3.05 & 109 & 164 \\
\hline All & 597 & 3.04 & 108 & 164. \\
\hline $\begin{array}{l}\text { Standard } \\
\text { deviation }\end{array}$ & & 0.59 & 27 & 23 \\
\hline
\end{tabular}

TABLE II - Mean plasma fibrinogen concentration ( $\mathrm{g} / \mathrm{l}$ ) in Hertfordshire men according to weight at 1 year and smoking habit. Numbers of men in parentheses

\begin{tabular}{llll}
\hline & \multicolumn{3}{c}{ History of smoking } \\
\cline { 2 - 4 } Weight at 1 year (lb) & Never smoked & Ex smoker & Current smoker \\
\hline$\leqslant 18$ & $2 \cdot 87(6)$ & $3 \cdot 25(19)$ & $3 \cdot 33(12)$ \\
-20 & $3 \cdot 25(11)$ & $2 \cdot 94(48)$ & $3 \cdot 28(31)$ \\
-22 & $2 \cdot 98(31)$ & $3 \cdot 10(96)$ & $3 \cdot 29(50)$ \\
-24 & $2 \cdot 81(32)$ & $2 \cdot 95(97)$ & $3 \cdot 14(42)$ \\
-26 & $2 \cdot 78(16)$ & $2 \cdot 93(46)$ & $3 \cdot 05(18)$ \\
$>26$ & $2 \cdot 62(4)$ & $3 \cdot 00(22)$ & $2 \cdot 87(7)$ \\
\hline All & $2 \cdot 90(100)$ & $3 \cdot 01(328)$ & $3 \cdot 20(160)$ \\
\hline
\end{tabular}

TABLE III-Mean plasma fibrinogen and factor VII concentrations according to systolic blood pressure in Hertfordshire men

\begin{tabular}{lccc}
\hline $\begin{array}{l}\text { Systolic pressure (mm Hg) } \\
\text { (adjusted for age, room } \\
\text { temperature, and body mass) }\end{array}$ & No of men & $\begin{array}{c}\text { Fibrinogen (g/l) (adjusted for } \\
\text { age, smoking, alcohol, and } \\
\text { waist to hip ratio) }\end{array}$ & $\begin{array}{c}\text { Factor VII (\% of standard) } \\
\text { (adjusted for waist to hip ratio } \\
\text { and body mass) }\end{array}$ \\
\hline$\leqslant 140$ & 83 & $2 \cdot 98$ & 107 \\
-150 & 81 & $2 \cdot 94$ & 106 \\
-160 & 111 & $2 \cdot 96$ & 108 \\
-170 & 120 & $3 \cdot 10$ & 107 \\
-190 & 115 & $3 \cdot 12$ & 112 \\
$>190$ & 87 & $3 \cdot 14$ & 108 \\
\hline All & 597 & $3 \cdot 04$ & \\
\hline
\end{tabular}

When the men were grouped into current smokers, ex-smokers, and those who had never smoked (histories for three men were unclassifiable) mean plasma fibrinogen concentration was highest in smokers and higher in ex-smokers than in men who had never smoked (table II). Adjustment for smoking did not change the trend in mean plasma fibrinogen concentration with weight at 1 year. Regression analysis showed that the concentration fell with increasing weight at 1 year in each smoking group (table II). Plasma fibrinogen concentration was lower in men who drank alcohol, the mean value being $2.94 \mathrm{~g} / 1$ in men who drank more than two units of alcohol a day compared with $3.06 \mathrm{~g} / \mathrm{l}$ in the remainder. Adjustment for alcohol consumption did not change the trends with weight at 1 year. Mean fibrinogen concentration was not related to body mass index (weight/height ${ }^{2}$ ). It was, however, higher in men with larger waist to hip ratios, rising by $0 \cdot 11 \mathrm{~g} / 1$ with each increase in waist to hip ratio of $0 \cdot 1$. Adjustment for waist to hip ratio did not change the trends with weight at 1 year.

Fibrinogen concentration was lower in taller men. Simultaneous regression of concentration on current height, birth weight, and weight at 1 year showed a significant trend with only weight at 1 year. Fibrinogen concentration fell by $0.03 \mathrm{~g} / \mathrm{l}(95 \%$ confidence interval 0.005 to 0.047 ) with each pound increase in weight at 1 year. In contrast, it fell by only $0.003 \mathrm{~g} / 1$ with each centimetre increase in height $(-0.004$ to 0.012$)$ and by $0.003 \mathrm{~g} / \mathrm{l}$ with each pound increase in birth weight $(-0.039$ to 0.046$)$.

Plasma factor VII concentration was not related to smoking or alcohol consumption. It rose, however, by $0.7 \%$ of the standard with each unit increase in body mass index $\left(\mathrm{kg} / \mathrm{m}^{2}\right)$ and by $0.6 \%$ of the standard with each $0 \cdot 1$ increase in waist to hip ratio. Adjustment for body mass index and waist to hip ratio did not change the trends with weight at 1 year (table I). Similarly to fibrinogen, the concentration of factor VII was lower in taller men, but in a simultaneous regression of factor VII concentration with height, birth weight, and weight at 1 year there was a significant trend with only weight at 1 year.

Neither fibrinogen nor factor VII concentration was related to current social class or social class at birth, after adjustment for age, smoking, alcohol intake, body mass index, and waist to hip ratio.

Details of infant feeding were recorded for $588 \mathrm{men}$ : 417 were exclusively breast fed, of whom 306 were weaned by 1 year; 143 were breast and bottle fed; and 28 were exclusively bottle fed. Mean plasma fibrinogen and factor VII concentrations did not differ according to the method of feeding. In all, 411 of the men were recorded as having had one illness or more during infancy. Their mean fibrinogen and factor VII concentrations did not differ from the remainder. Neither did those of men who had had specific illnesses including bronchitis, bronchopneumonia, measles, whooping cough, and diarrhoea.

Systolic blood pressure rose by $0.7 \mathrm{~mm} \mathrm{Hg}$ with each year of age, fell by $1.2 \mathrm{~mm} \mathrm{Hg}$ with every degree centigrade of room temperature, and rose by $1.1 \mathrm{~mm}$ $\mathrm{Hg}$ with each unit of body mass index. In contrast to mean fibrinogen and factor VII concentrations, mean systolic pressure fell with increasing birth weight $(p=$ 0.003 ) but showed no significant trend with weight at 1 year (table I) or with height. Table III shows variations in mean plasma fibrinogen and factor VII concentrations in relation to systolic pressure, after the other variables had been adjusted for. Plasma fibrinogen concentration was strongly related to systolic pressure, rising progressively with increasing pressure $(p=0.005)$; plasma factor VII concentration was only weakly positively related to blood pressure $(p=0 \cdot 12)$ and to fibrinogen concentration $(p=0 \cdot 12)$. 
PRESTON MEN

Satisfactory measurements of fibrinogen and factor VII concentrations were obtained for 142 of the 148 men. Plasma fibrinogen concentration increased with age, cigarette smoking, and larger waist to hip ratio but was not related to alcohol intake or social class. As in the Hertfordshire men fibrinogen concentration was not significantly related to birth weight. Simultaneous analysis of birth weight and placental weight, however, showed that it fell with increasing birth weight $(p=$ $0.06)$ and rose with increasing placental weight $(p=0 \cdot 03)$. The lowest mean plasma fibrinogen concentration $(2.82 \mathrm{~g} / \mathrm{l})$ was in men who had weighed more than $7.5 \mathrm{lb}$ at birth, with a placental weight of $1.25 \mathrm{lb}$ or less (table IV). The highest value $(3 \cdot 11 \mathrm{~g} / \mathrm{l})$ was in men who had weighed $6.5 \mathrm{lb}$ or less, with a placental weight greater than $1.25 \mathrm{lb}$. Mean plasma fibrinogen concentration rose progressively as the ratio of placental weight to birth weight increased $(p=0.01$, table V). These trends were independent of duration of gestation, which was known for 108 of the men.

We examined the separate associations of plasma fibrinogen concentration with head circumference, length, and ponderal index (birth weight/length ${ }^{3}$ ) at birth. Simultaneous analysis with placental weight showed that fibrinogen concentration tended to rise as length decreased $(p=0.08)$, from $2.83 \mathrm{~g} / \mathrm{l}$ in men who were 21 inches or longer at birth to $3.06 \mathrm{~g} / \mathrm{l}$ in men who were less than 20 inches. Concentration was not associated with head circumference or ponderal index.

Factor VII concentration in the men in Preston was not associated with body mass index or waist to hip ratio. As in Hertfordshire men it was not related to birth weight, nor was it related to the placental weight to birth weight ratio (table V). Factor VII concentration tended to fall with increasing gestation $(p=0.08$, table VI).

\section{Discussion}

We have shown that plasma concentrations of fibrinogen and factor VII in adult men are strongly linked with growth in infancy. Both fell progressively with increasing weight at 1 year (table I). The difference in concentrations between men who had weighed $27 \mathrm{lb}$ or more at 1 year and those who had weighed $18 \mathrm{lb}$ or less was statistically equivalent to an increase in

TABLE IV-Mean plasma fibrinogen concentration ( $g / l)$, adjusted for age, according to birth and placental weights in Preston men aged 46 54. Numbers of men in parentheses

\begin{tabular}{llll}
\hline & \multicolumn{2}{c}{ Placental weight $(\mathrm{lb})$} & \\
\cline { 2 - 3 } Birth weight $(\mathrm{lb})$ & $\leqslant 1.25$ & $>1.25$ & All \\
\hline$\leqslant 6.5$ & $3.00(31)$ & $3.11(15)$ & $3.04(46)$ \\
-7.5 & $2.95(28)$ & $2.93(22)$ & $2.94(50)$ \\
$>7.5$ & $2.82(11)$ & $2.87(35)$ & $2.85(46)$ \\
\hline All & $2.95(70)$ & $2.94(72)$ & $2.94(142)$ \\
\hline
\end{tabular}

TABLE $\mathrm{v}-$ Mean plasma fibrinogen concentration, adjusted for age, and mean factor VII concentration in Preston men according to ratio of placental to birth weight

\begin{tabular}{lccc}
\hline $\begin{array}{l}\text { Ratio of placental } \\
\text { to birth weight }\end{array}$ & No of men & Fibrinogen $(\mathrm{g} / \mathrm{l})$ & $\begin{array}{c}\text { Factor VII (\% of } \\
\text { standard) }\end{array}$ \\
\hline-0.162 & 28 & 2.87 & 113 \\
-0.182 & 30 & 2.89 & 113 \\
-0.200 & 27 & 2.92 & 110 \\
-0.229 & 28 & 2.90 & 111 \\
$>0.229$ & 29 & 3.15 & 107 \\
\hline All & 142 & 2.94 & 111 \\
\hline Standard deviation & & 0.50 & 30 \\
\hline
\end{tabular}

TABLE VI-Mean plasma factor VII concentration according to weeks of completed gestation in Preston men

\begin{tabular}{lrrrr}
\hline Weeks of gestation & -38 & -40 & $>40$ & All \\
\hline $\begin{array}{l}\text { Mean plasma factor VII }(\% \text { of } \\
\text { standard) }\end{array}$ & 119 & 118 & 103 & 113 \\
No of men & 30 & 41 & 37 & 108 \\
\hline
\end{tabular}

cardiovascular death rate of around $40 \%{ }^{3}$ This is likely to underestimate the strength of the associations as the weights of the babies were imprecise. Babies were weighed at home with simple scales, and their weights were often rounded to the nearest half pound.

The study samples comprised men who were born in east Hertfordshire during 1920-30, who were still living there, and men born in Sharoe Green Hospital, Preston, and still living in or close to the town. As our analysis was based on internal comparisons the selection of the sample would introduce bias only if the relations between early growth and plasma fibrinogen and factor VII concentrations were different in those selected and not selected. This is unlikely. The same relations were found in each social class.

High fibrinogen concentration increases blood viscosity and enhances platelet aggregability and, in rabbits, determines the amount of fibrin deposited when coagulation is initiated. ${ }^{10}$ It is suspected to contribute to the development and progression of atheroma. Fibrinogen is an acute phase protein and rises in response to several stimuli. ${ }^{11}$ Factor VII, which does not respond to such stimuli, is a key component of the extrinsic coagulation system and thus in the production of thrombin. Both fibrinogen and factor VII may thus have a causal role in ischaemic heart disease.

Consistent with previous findings, a higher plasma fibrinogen concentration was associated with age, smoking, low alcohol intake, and waist to hip ratio..$^{1213}$ A higher plasma factor VII concentration was associated with higher body mass index and waist to hip ratio. The trends with weight at one year were not changed by adjustment for these variables. The simultaneous relation of fibrinogen concentration with smoking and weight at 1 year (table II) indicates that effects of the adult environment add to those associated with failure of infant growth.

\section{INFLUENCE OF CONFOUNDING VARIABLES}

It may be argued that people born into an adverse environment tend to remain there. Therefore the association between lower weight at 1 year and higher adult concentrations of haemostatic factors could reflect the cumulative effects of adverse influences acting throughout a person's life. After smoking and other known confounding variables had been allowed for, however, average concentrations of fibrinogen and factor VII were not higher in men of lower social class, as would be expected from this argument. Furthermore, they were not independently related to adult height or to birth weight, but only to weight at 1 year. An association with short adult stature would be expected if they were determined by adverse influences acting throughout the period of growth. The argument that higher fibrinogen concentration reflects influences in only the current environment which trigger the acute phase response is not consistent with the absence of a social class gradient in fibrinogen concentration in our study. Nor could it apply to factor VII concentration as factor VII does not rise as part of the acute phase response.

It could also be argued that the link between early growth and adult plasma fibrinogen and factor VII concentrations reflects genetic influences. Studies using restriction fragment length polymorphisms of the fibrinogen genes showed that genetic variation could 
account for at least $15 \%$ of the total variance in plasma concentration..$^{14}$ Fetal and infant growth are, however, strongly influenced by maternal physique, health, and nutrition, and we therefore favour an environmental explanation for our findings.

\section{INFLUENCE OF RESTRICTED GROWTH IN EARLY LIFE}

Our results suggest that there may be a critical period in early life when growth is linked with the setting of plasma concentrations of haemostatic factors. Research in animals has shown that influences which restrain growth during critical periods of early life may permanently affect organ size and function. ${ }^{15} 16$ For example, in rats weaned on to a low protein diet for only three weeks the insulin response to glucose was permanently impaired. ${ }^{17}$ This phenomenon, known as "programming," has been shown in a wide range of tissues. Circulating fibrinogen and factor VII concentrations are largely regulated by the liver. The high adult concentrations associated with reduced infant growth may be a persisting response to impaired liver development during a critical early phase. Plasma concentrations of fibrinogen and factor VII reach values within the adult range by the age of 1 year. ${ }^{18}$

Growth failure in infancy may result from either postnatal or prenatal influences. Postnatal influences include feeding and illness. Concentrations of the haemostatic factors in the Hertfordshire men did not vary in relation to differences in infant feeding and weaning, although these differences were related to adult cholesterol concentrations (unpublished data). Neither were they related to illness during infancy, although the occurrence of bronchitis or bronchopneumonia was associated with impaired adult lung function in these men.

The findings in Preston suggest that prenatal influences may underlie the reduction in infant growth which is associated with high plasma concentrations of fibrinogen. Although fibrinogen concentration was not related to birth weight, simultaneous analysis of birth weight and placental weight disclosed that it fell with increasing birth weight and rose with increasing placental weight (table IV). The highest concentration was in men with the highest ratio of placental weight to birth weight (table V). These trends were independent of gestation.

Low birth weight for placental weight may be interpreted as a sign of fetal growth failure. ${ }^{19}$ Previous analyses of the Preston data showed that high blood pressure is also related to low birth weight for placental weight. ${ }^{9}$ Failure of a fetus to achieve the size expected from its placental weight occurs in babies within the normal range of birth weight (table IV). It is not confined to low birth weight babies, as defined by conventional criteria for intrauterine growth retardation. Some low birth weight babies, conventionally defined, have disproportionate retardation of growth of the abdominal viscera, especially the liver, as growth of some other organs, notably the brain, tends to be protected..$^{20}$ Whether reduced liver size is also a characteristic of babies with low birth weight for placental weight is not known. Reduced liver growth in utero could lead to long term changes in fibrinogen metabolism.

The pattern of infant growth which follows retarded intrauterine growth differs according to whether the babies are short at birth or thin, as measured by low ponderal index. ${ }^{21} 22$ Thin babies tend to "catch up" in weight whereas short babies do not. In our data fibrinogen concentration was associated with shortness but not thinness. High adult fibrinogen concentration and infant growth failure may therefore be associated through a common origin in fetal growth failure.

In the Preston data high blood pressure was found in babies who were short and also in those who were thin. ${ }^{19}$ The tendency for thin babies to have below average birth weights but to catch up in infancy may explain why high blood pressure in Hertfordshire men was associated with low birth weight but not with weight at 1 year (table I). Association of both fibrinogen concentration and blood pressure with low birth weight for placental weight is consistent with the close relation between fibrinogen concentration and blood pressure in adults, as shown in our data (table III) and in previous studies. ${ }^{2324}$

Similarly to the Northwick Park study, ${ }^{3}$ we found that factor VII concentration was only weakly associated with either fibrinogen concentration or blood pressure level (table III). This is consistent with it having no association with birth weight or placental weight (table V). We found that factor VII concentration tended to be higher in men born before 40 weeks' gestation (table VI). The association was based on only 108 men whose gestation period was known and was not significant; it is interesting, however, as in the neonate factor VII concentration is linked with duration of gestation. ${ }^{18}$ Our data gave no other indication that prenatal influences contribute to the association between reduced infant growth and high plasma factor VII concentration.

We conclude that the control of haemostasis in adults is partly programmed by the intrauterine and infant environments. Added to recent findings that fetal and infant growth is linked with adult blood pressure $^{9}$ and glucose tolerance, ${ }^{25}$ this is further evidence of the importance of fetal and infant development in the genesis of cardiovascular disease.

We thank all the men who gave us their time; also Hertfordshire County archives and the medical records department at Sharoe Green Hospital, Preston, which preserved the records and allowed us to use them; and the staff at the NHS central register, Southport, and of Hertfordshire and Lancashire Family Health Services Authorities, who traced the subjects. We thank Dr I Clarke, east Hertfordshire district community physician, for much local help. The fieldwork in Hertfordshire was carried out by P Harwood, $S$ Haynes, $P$ Howell, $R$ Rosenthal, and $S$ Wolfe, and that in Preston by J Hart, M Livesey, and J Peace. B E Newland, Princess Alexandra Hospital, Harlow, and the laboratory staff at the Royal Preston Hospital stored the blood samples. The study was funded by the Medical Research Council, the Dunhill Medical Trust, and the Wessex Medical Trust.

1 Barker DJP. The intrauterine origins of cardiovascular and obstructive lung disease in adult life. $\mathcal{F} R$ Coll Phys Lond 1991;25:129-33.

2 Barker DJP, Winter PD, Osmond C, Margetts B, Simmonds SJ. Weight in infancy and death from ischaemic heart disease. Lancet 1989;ii:577-80.

3 Meade TW, Mellows S, Brozovic M, Miller GJ, Chakrabarti RR, North WRS, et al. Haemostatic function and ischaemic heart disease: principal results the Northwick Park heart study. Lancet 1986;ii:533-7.

4 Meade TW. The epidemiol artery disease. In: Verstraete M, Vermiylen J, Lijnen R, Arnour J, eds. artery disease. In: Verstraete M, Vermiylen J, Lijnen R, Arnout J, eds. 37-66.

5 Barker DJP, Godfrey KM, Fall C, Osmond C, Winter PD, Shaheen SO. The relation of birth weight and childhood respiratory infection to adult lun function and death from chronic obstructive airways disease. BMF 199 ; 303:671-5

6 Office of Population Censuses and Surveys. Classification of occupations 1980 London: HMSO, 1980.

7 Clauss A. Gerinnungsphysiologische Schnellmethode zur Bestimmung de Fibrinogens. Acta Haematol (Basel) 1957;17:237-46.

8 Brozovic M, Stirling Y, Harricks C, North WRS, Meade TW. Factor VII in an industrial population. $\mathrm{Br} f$ Haematol 1974;28:381-91.

9 Barker DJP, Bull AR, Osmond C, Simmonds SJ. Fetal and placental size and risk of hypertension in adult life. $B M \mathcal{F} 1990 ; 301 \cdot 259-62$.

10 Gureweich V, Lipinski B, Hyde E. The effect of the fibrinogen concentration and the leucocyte count on intravascular fibrin deposition from soluble fibrin monomer complexes. Thromb Haemost 1976;36:605-14.

11 Brozovic M. Physiological mechanisms in coagulation and fibrinolysis. Br Med Bull 1977.33:231-8.

12 Meade TW, Chakrabarti R, Haines AP, North WRS, Stirling Y. Characteristics affecting fibrinolytic activity and plasma fibrinogen concentration. $B M 7$ 1979;i:153-8.

13 Lee AJ, Smith WCS, Lowe GDO, Tunstall-Pedoe H. Plasma fibrinogen and coronary risk factors: the Scottish heart health study. I Clin Epidemiol 1990;43:913-9.

14 Humphries SE, Cook M, Dubowitz M, Stirling Y, Meade TW. Role of genetic variation at the fibrinogen locus in determination of plasma fibrinogen concentrations. Lancet 1987;ii: 1452-6. 
15 Dubos R, Savage D, Schaedler R. Biological Freudianism: lasting effects of early environmental influences. Pediatrics 1966;38:789-800.

16 Winick $M, N o b l e A$. Cellular response in rats during malnution at vaious ages. I Nutr 1966;89:300-6.

17 Swenne I, Crace CJ, Milner RDG. Persistent impairment of insulin secretory response to glucose in adult rats after limited period of protein-calori malnurition early in life. Diabetes 1987:36:454-8.

18 Andrew $M$, Paes B, Johnston $M$. Development of the hemostatic system in the neonate and young infant. Am $\mathcal{F}$ Pediatr Hematol Oncol 1990;12:95-104.

9 Barker DJP, Godfrey KM, Osmond C, Bull A. The relation of fetal length, ponderal index and head circumference to blood pressure and the risk of hypertension in adult life. Paediatr Pernat Eprdemiol (in press).

20 Gruenwald P. Chronic fetal distress and placental insufficiency. Biol Neona $1963 ; 5: 215-65$

21 Holmes GE, Miller HC, Hassanein K, Lansky SB, Goggin JE. Postnatal somatic growth in infants with atypical fetal growth patterns. Am $\mathcal{f}$ Dis Child 1977; 131:1078-83.

22 Villar J, Smeriglio V, Martorell $\mathrm{R}$, Brown $\mathrm{CH}$, Klein RE. Heterogeneous growth and mental development of intrauterine growth retarded infants during ane firs 3 yen of life. Pediat 1984;74:783-91.

23 Kannel WB, Philip AW, Castelli WP, D'Agostino RB. Fibrinogen and risk of cardiovascular disease. The Framlingham study. fAMA 1987;258:1183-6 24 Wilhelmsen L, Svardsudd K, Korsan-Bengtsen K, Larsson B, Welin L, Tibblin G. Fibrinogen as a risk factor for stroke and myocardial infarction. New Engl F Med 1984;311:501-5.

25 Hales CN, Barker DJP, Clark PMS, Cox LJ, FAll C, Osmond C, et al. Fetal and infant growth and impaired glucose tolerance at age 64 years. $B M \gamma$ 1991;303:1019-22.

(Accepted 17 October 1991)
Walton Hospital, Liverpool

IA MacFarlane, $M D$

consultant physician

G V Gill, MD, consultant

physician

E Masson, MD, senior registrar

in medicine

H M Prison, Liverpool

N H Tucker, MB, head of medical services

Correspondence to:

Dr I A MacFarlane,

The Diabetes Centre,

Walton Hospital, Liverpool

L91 AE.

BMF 1992;304:152-5 ideal diabetic care by medical personnel trained in diabetes during long prison sentences.

In 1989 one of us (IAM), a consultant physician and diabetologist in Liverpool, became the visiting physician to HM Prison, Walton, Liverpool. This entails holding an afternoon medical clinic about every two weeks, when any medical problems noted by the prison medical staff are referred for a further opinion. Common conditions include ischaemic heart disease, hypertension, and diabetes. There has been no previous prospective study of the management of diabetes in British prisons. This paper therefore examines in detail all prisoners with diabetes seen in the clinic over 22 months and reports their metabolic control. We also discuss methods of achieving optimal diabetic care in a prison environment. Between the initial assessment by the visiting consultant diabetologist and a second assessment 10 weeks later glycated haemoglobin concentrations had fallen from 10.8 (SD 2.9 ) $\%$ to $9.8(2.4) \%$ $(\mathbf{p}<0.05)$ in prisoners with insulin dependent diabetes and from $8.7(1.9) \%$ to $7.6(1.2) \%(p<0.05)$ in those with non-insulin dependent diabetes. Good glycaemic control continued, a mean glycated haemoglobin concentration of $7.6(1.5) \%$ being recorded in seven men remaining in prison for six to 18 months. Mean body mass index (weight (kg)/ (height $(\mathbf{m}))^{2}$ ) did not change during the study (insulin dependent prisoners 23.3 (SD 2.1), non-insulin dependent prisoners $27 \cdot 9(3 \cdot 8)$ ).

Conclusions-Good diabetic metabolic control is usual in prison, probably due to the rigid dietary regimen, no alcohol, and compliance with treatment. Many younger men had defaulted from their home diabetic clinics, and imprisonment allowed screening for diabetic complications and reassessment of treatment. Structured diabetic care should be offered in all prisons.

\section{Introduction}

The conditions experienced by people in custody in the United Kingdom have received considerable attention recently, particularly after the serious disturbances in prisons in Manchester and elsewhere during 1990. Also there has been much debate concerning the standards of health care in British prisons. ${ }^{1-5} \mathrm{~A}$ major problem is the paucity of data on specific medical conditions, although suicide, drug abuse, and HIV infection have received particular attention ${ }^{6-8}$ In a previous report we highlighted difficulties in delivering diabetic care in prisons. ${ }^{9}$ These included self induced diabetic ketoacidosis by prisoners refusing insulin in order to be transferred to the local hospital; prison staff misinterpreting poorly controlled diabetes as "acting up" by prisoners; and difficulty of delivering

\section{Patients and methods}

Walton prison has about 1500 inmates and is one of the largest prisons in Britain. During 22 months (August 1989 to May 1991) all prisoners with diabetes identified by the prison medical officers were referred to the medical clinic held in the prison hospital. For each prisoner with diabetes the following were recorded: weight and height; type, duration, metabolic control (glycated haemoglobin concentration), and treatment of the diabetes; diabetic complications present; other medical illnesses and treatments; and smoking habits. A record was kept of alterations in the medical management initiated in the clinic. The views of the prisoners on the prison diet, exercise facilities, and medical management in prison were also recorded

The prison has a mixture of remand (before conviction; roughly $20-25 \%$ ) and convicted prisoners, all male. The period of remand may vary from days to many months. Sentences also vary from a few days to life imprisonment but are usually between four and 18 months. Walton is a traditional Victorian prison and is undergoing extensive refurbishment. Many prisoners, however, continue to share cells with communal sanitation facilities. Exercise is usually limited to about an hour's walking in the yard each day. The 60 bed prison hospital is staffed by five full time medical officers and is a referral centre for major medical, surgical, and psychiatric problems occurring in smaller prisons in the north west. Many prisoners are moved to other establishments several times during their sentence.

All the prisoners with diabetes are entitled to extra fruit, yoghourt, and night time digestive biscuits (to reduce the risk of nocturnal hypoglycaemia). The administration of oral hypoglycaemic drugs and insulin injections is supervised by the prison hospital officers. Prisoners are not allowed to keep tablets, 